\title{
The Effect of Second Language Writing Ability on First Language Writing Ability
}

\author{
Nastaran Mehrabi \\ Islamic Azad University of Khorasgan, Isfahan, Iran
}

\begin{abstract}
This study was conducted to investigate the influence of second language writing ability on first language writing ability. To do so, two different groups of university students, majoring in English and nonEnglish (nursing), were chosen to write compositions on a topic of their interest. At first, students in both groups were asked to write about 200 words on a topic in their first language. Then, the students studying English passed a course in writing which was called Grammar and Writing Course 1. During the course, they were taught paragraph and essay writing in second language (English). After passing the course, both groups were asked to write on the same topic in their first language again. Then, 30 compositions of each group were chosen randomly and they were scored on a scale of 0 to 20 by two qualified Persian raters. In compositions, reasoning, understanding the purpose of the task, vocabulary choice, structural well-formedness, developing ideas, presenting connected ideas, punctuation, and style were identified. Finally, appropriate statistical operations, including t-test, were used to analyze the data. The results indicated that $\mathrm{L} 2$ learning is effective on the development of $L 1$ skill and writing ability in $L 2$ affects $L 1$ writing ability.
\end{abstract}

Index Terms — first language writing ability, second language writing ability

\section{INTRODUCTION}

Learning a second language involves the handling of four basic skills; listening speaking, reading, and writing. Writing is the ultimate skill that learners should master. It is a basic communication skill that cannot be acquired; it can be culturally transmitted or can be learned through formal instruction. Among the four skills of language, writing and speaking are productive skills. Of course, there are important differences between them. All normal people learn to speak while writing should be taught to them. In comparison to speaking, writing imposes greater demands on the learners since there is no immediate feedback in written interaction. The writer has to anticipate the reader's interaction and make a text which adheres to Grice's (1975) cooperative principle. According to this principle, the writer should try to write a clear, relevant, truthful, informative, interesting, and memorable text. The reader, on the other hand, interprets the text with regard to the writer's presumed intension if the necessary clues are available in the text. Linguistic accuracy, clarity of presentation, and organization of ideas are all essential in the efficacy of the communicative act, since they provide the necessary clues for interpretation.

Broadly speaking, writing requires a greater in-depth knowledge of the grammar system than the receptive skills and perhaps even than speaking. Writing both in practical sense and in the communicative sense, entails unique features that result in distinct contributions to overall language learning. Writing anything to be learned assists learners to practice and rehearse the material and store it in long-term memory. Although seeing the language in written form is not essential for some students, for others the vocabulary, grammar, and patterns are easily learned by writing and looking at what they are to learn.

Writing emerged in societies as a result of cultural changes that created new communication needs. Writing is important because it is a basis for communicating clear thinking. The development of writing skill is a complex and dynamic cognitive process because it requires more than the mastery of vocabulary and linguistic competence.

Writing is considered as a means of learning language forms and a way of communication. Language teachers should incorporate both types into their classes and they should develop classroom activities that include both communication and language forms.

The ability to write well is not a naturally acquired skill. Writing skills must be practiced and learned through experience. Writing also involves composing which implies the ability either to tell or retell pieces of information in the form of narratives or description, or transform information into new texts, as in expository or argumentative writing. Perhaps it is best viewed as a continuum of activities that range from the more mechanical or formal aspects of 'writing down' on the one end, to the more complex act of ' composing ' on the other end (Omaggio Hadley, 1993).

\section{LITERATURE REVIEW}

Writing plays an important role in our personal and professional lives, thus, it has become one of the essential components in university curricula. Second language writing has always been a difficult area for second language learners and a hot topic for second language researchers. To state it differently, the field of L2 writing is a fairly recent phenomenon. Historically speaking, the field of L2 writing originally emphasized on the teaching of writing to the 
increasing population of international ESL writers at institution of higher education in North America in the late 1950s and the early 1960s. During the last 50 years, the number of inquiries into L2 writing issues have grown rapidly and produced results.

Leki, Cumming, and Silva (2008) point out that the last 30 years have seen several firsts in L2 writing research.

\section{A. Various Contexts of Second Language Learning}

There are two mains concepts of second language learning; submersion programmes and immersion programmes. They lead to subtractive and additive bilingualism respectively.

\section{Subtractive bilingualism; Submersion programmes in the United States}

The terms "subtractive" and "additive" bilingualism were coined by Lambert (1964). The significant factor dividing two kinds of bilingualism is social. A good example of submersion programme in the U.S.A is Mexican children. In this case, children's first language is Spanish while they are schooled from the beginning in English that is their new second language. In other words, their first language (Spanish) is slowly replaced and is being "subtracted out" (Lambert, 1992, p.213).

These minority children are forced to assimilate into the mainstream culture while their L1 system has not been developed yet, and they do not develop it further. This deficiency in both languages (Spanish and English) is called "semi-lingualism" (Skutnabb-Kangas and Toukomma).

Submersion programme had negative effects like eliminating minority children's language, weakening their cultural identity and putting them at risk in academic achievement. Thus, bilingual education has been an important political issue in the United States. In order to remedy this situation, "transitional" programmes have been introduced. In these programmes, children are schooled in reading and writing in their first language in the first school years. At the same time, English language (L2) is taught to them. By using this programme, a time of transition is being provided between schooling in the first language and learning L2 in order to use it as the language of instruction. The children would have a positive attitude toward their own culture.

Cummins (1996) concluded "that strong promotion of minority students' L1 throughout elementary school contributes significantly to academic success" (p.121). Despite the effort made, transitional programmes as well as submersion programmes lead to subtractive bilingualism. They lead to monolinguality in English by the end of elementary school.

\section{Additive bilingualism; Immersion programmes in Canada}

In this situation the first language is the majority language. In Canada English speaking students enter a French immersion or a core French programme. In a core French programme, students are taught French (as a second language) about 30 minutes a day. In immersion programme, there is "early immersion" (starting in kindergarten or grade 1), "mid-immersion" (starting in grade 4) or "late immersion" (starting in grade 6 or 7). Also there is variation of model throughout Canada in teaching all or some of the subjects in the second language. Programmes can be identified as either partial (a few subjects, about 50\% in L2) or total immersion (all instruction in L2). When only one subject and language arts are taught in the second language, the programme is "enriched second language programme". In immersion, both languages have social value. L1 is further developed at school, in the family and other situations outside the school. Since L2 is an addition to the L1 competence, this type of bilingualism is called "additive" bilingualism (Lambert, 1964; 1975; 1990).

The difference between two types of programmes and situational context is important. Cummins illustrates these differential results with two hypotheses, the threshold hypothesis and the interdependence hypothesis. These hypotheses are often used to explain the results about the effect of second language learning on first language skills and other domains.

\section{B. Cummins' Hypotheses}

\section{Cummins' threshold hypothesis}

Cummins postulated his "threshold hypothesis" by comparing the immersion and submersion situation, considering the results of both groups, and looking at linguistic social and school programme factors. Threshold hypothesis explains that the learner's level of L1 competence already reached by him or her determines if she or he will experience cognitive deficits or benefits from schooling in the second language (Cummins, 1976; 1978a). To state it differently, students have a certain "threshold" in first language competence. When the first language is minority language in the community this threshold level has not been reached yet and their L1 is not fully developed. But when the first language is the language of majority children, they have developed this threshold.

Cummins (1979) developed this hypothesis and represented that there is a threshold for L2 which must be attained to influence a student's cognitive and academic functioning (Cummins, 1979, p.222).

\section{Cummins' developmental interdependence hypothesis}

Cummins (1984) described the interdependence hypothesis as follow:

"to the extent that instruction in Lx is effective in promoting proficiency in Lx, transfer of this proficiency to Ly will occur provided there is adequate exposure to Ly (either in school or environment) and adequate motivation to learn Ly." (Cummins, 1984, p.41). 
In other words, Cummins believes that when the usage of L1 is promoted by the child's linguistic environment outside the school, then a high level of L2 achievement occurs. Conversely, when the child has not developed L1 sufficiently, low level of L2 is the result. Thus, there is an interaction between child's L1 competence and the language of instruction.

Cummins (1983) explains that L1 and L2 are manifestations of " common underlying proficiency". Moreover, L1 and L1 literacy skills are interdependent. To state it differently, high level of L1 proficiency can help L2 acquisition, and high proficiency in L2 can have a positive effect on L1 development.

\section{Effects of Learning a Second Language on First Language Skills in Context}

Much of the research has been done about the influence of the first language on the second language (Harley, Cummins, Swain, \&Allen, 1990), and the result is that in developing second language, mother tongue is an important factor. On the contrary, there has been research about the influence of second language learning on first language literacy skills especially in studies in immersion education. The fact that bilingual students often outperform the unilingual was shown by studies (Cummins, 1980).

The first French immersion programme in Montreal in 1965 was investigated by Lambert and Tucker (1972). The goal of the experiment was to provide English-speaking children with functional competence in written and spoken French. During kindergarten and grade 1 all instruction was in French while in grade 2 English language arts instruction was introduced. An immersion student group and an English control group were compared after grade 1, 2, 3, and 4 by Lambert and Tucker. They found that the immersion group scored lower in English literacy skills such as reading comprehension, spelling, and written vocabulary before starting English instruction (Lambert and Tucker, 1972, p.45).

However, by the end of grade 2 this lag was made up (p.103). The immersion group did not fall behind in oral English skills like listening comprehension, and oral production (Lambert and Tucker, 1972, p.45). Listening comprehension of the immersion group was equivalent to English control group. Students listened to a short story and answered multiple-choice questions. Furthermore, their speaking was examined by asking them to create a story based on a comic strip. The stories were also equivalent to those of the English control group.

In a study carried out by Genesee, Tucker, and Lambert (1975) it was found that total immersion and partial immersion students on an interpersonal communication task performed better than students in regular English schools. Genesee (1979) reported high correlation between reading skills in L1 and L2. In other words, he concluded that reading skills are transferred from one language to the other. Here also, there is correspondence between this explanation and Cummins' hypothesis.

Immersion studies in Toronto and Ottawa, Ontario were carried out by Swain and Lapkin (1982). They were interested in investigating whether immersion programme has effect on students' first language (English) skills. In their study, the results show that when literacy skills of one language are established, they can be transferred to the other language.

Verhoeven (1994) investigated the relationship of students' L2 and L1. In this study 98 six-year-old Turkish children lived in Netherlands were compared. Turkish was their L1 and their L2 was Dutch. In both languages, Verhoeven looked at the development of literacy and found out that lexical and morpho-syntactic skills developed autonomously (p.408) and in phonological skills there was a moderate interdependence. However, a strong positive transfer from L1 to L2 was shown in pragmatic skills and reading abilities. Thus, reading skills are interdependent across languages. In Hong Kong, in a large scale longitudinal study the effect of immersion education on the achievement of students in Chinese, with Chinese as L1 and English as L2, was investigated (Marsh et al.,2000). The results show that when students are instructed in English their achievement in the first language (Chinese) and second language (English) were enhanced.

The findings support Cummins' interdependence hypothesis: L2 abilities are transferred from L1 when both languages are developed to a high degree. It means that thinking and language abilities are developed in one language and transferred to the other. There is a "mutually beneficial interplay between L2 and L1" (Lambert, 1990, p.217).

In the research community, Cummins' theory is a controversial issue since there is no definition to the "threshold level necessary" and the theory cannot be supported experimentally. Some researchers such as Geva and Ryan (1993) suggest other variables to explain the results found. They state that there are some other variables like individual differences in intelligence and memory span (p.37).

\section{Methodology}

\section{A. Participants}

The study was conducted on two different groups (30 students each) of university students. The first group consisted of 30 male and female students studying English at Esfahan University, and the second group included 30 male and female students studying nursing at Esfahan University. As far as both groups of students have passed university entrance exam, at the beginning of the study and before passing Grammar and Writing course 1 by English students, the level of their knowledge in general courses (like general English) would be the same. To compare the effect of L2 writing ability on the L1 writing ability, a group of English major students is compared with a group of non-English major students. So, nursing major is selected since students do not pass any course in writing while in English major do. 
Both groups were first-semester students. These students were selected from among 105 accessible university students. All the participants were Persian native speakers with almost the same Persian background knowledge. Their age ranged between 18 and 25 .

\section{B. Materials}

\section{Pretest}

In order to determine the impact of L2 writing course on L1 writing, before the beginning of the experiment, the students in both groups were asked to write in their first language at least 200 words on a topic (characteristics of a good friend). This is a descriptive topic and students describe a good friend. This topic was chosen since it was of students' interest and students had ideas to write about it.

\section{Writing task}

Then, in order to find out whether or not having a writing course in a second language has any impact on writing in the first language, after the English major students finished their course, once again the students in both groups were asked to write at least 200 words on the same topic (characteristics of a good friend) in their first language. The students were asked to write on a neutral subject, and the topic was the same for both groups. The topic chosen for the purpose of writing comprised a broad and general one which was not culture-bound or discriminatory.

\section{Procedure}

To accomplish the purpose of the study, the following procedures were employed. At first, two groups of firstsemester University students were selected (majoring in English and nursing). Then, both groups were asked to write on a topic about 200 words in their first language. Then, the students studying English passed a course in writing which was called Grammar and Writing course 1.

During the course, they were taught paragraph and essay writing in second language (English). After passing the course by the students studying English, both groups were asked to write on the same topic in their first language again. Then, the Persian passages were scored for their writing ability on a scale of 0 to 20 by two qualified Persian raters. The criteria which were taken into consideration in the writings were reasoning, understanding the purpose of the task, vocabulary-choice, structural well-formedness, developing ideas, presenting connected ideas, punctuation, and style. In order for our findings to be reliable and consistent, an interrater reliability has been conducted. To do this, two literate experts were asked to correct the writing compositions produced by the participants. The reason was that in comparison to translation and teaching experts, literature experts are more familiar with appropriate writing techniques and application of language conventions. Then, the scores were statistically analyzed. If there is a strong reliability, one can assume with reasonable confidence that raters are judging the same set of data as representing the same phenomenon. Therefore, interrater reliability was measured and it turned out to be .917 . Finally, the two sets of scores, that is, one set for English major students and one for nursing major students, were compared to find the probable differences.

\section{RESULTS AND DisCUSSION}

In this study an attempt was made to further our understanding of the role of second language writing ability on first language writing ability hoping that the findings can bring about a positive change in the writing of English and pave the way for the improvement of writing instruction. To this end, two sets of writing were compared together to answer the research question.

The first set of writing, which was written before the experiment, was corrected and scored by two raters. Table 4.1 gives the descriptive statistics of the pre-experiment writing scores. The scores reported here are the averages of the two ratings.

TABLE (4.1)

DESCRIPTIVE STATISTICS FOR THE PRE-EXPERIMENT WRITING

\begin{tabular}{lllll}
\hline Groups & $\mathrm{N}$ & Mean & SD & SEN \\
\hline English & 30 & 12.60 & 3.174 & .580 \\
Nursing & 30 & 12.40 & 2.581 & .471 \\
\hline
\end{tabular}

As it can clearly be seen, there is difference between the two means. In order to make sure that this difference is not significant, a t-test was run. Table 4.2 indicates the results of the t-test.

TABLE (4.2)

THE RESULT OF THE T-TEST ON THE PRE-EXPERIMENT WRITING

\begin{tabular}{llll}
\hline Sig. & & & \\
$\mathrm{T}$ & $\mathrm{df}$ & $(2$-tailed) & Mean Difference \\
\hline .268 & 58 & .790 & .200 \\
\hline
\end{tabular}

According to table 4.2 above, it can be claimed that the participants in the two groups were homogeneous regarding their ability in writing in Persian. Further analysis was applied to the scores of the post-experiment writings of the two groups to find out if the writing instruction in L2 had any effects on writing ability in L1. Table 4.3 shows the descriptive statistics of the post-experiment writings. 
TABLE (4.3)

DESCRIPTIVE STATISTICS FOR THE POST-EXPERIMENT WRITING

\begin{tabular}{lllll}
\hline Groups & $\mathrm{N}$ & Mean & SD & SEN \\
\hline English & 30 & 16.35 & 1.733 & .316 \\
Nursing & 30 & 12.32 & 2.066 & .377 \\
\hline
\end{tabular}

According to table 4.3 there is a 4.03-mark difference between the means of the two groups. In order to understand whether this difference is statistically significant or not, the researcher employed another t-test.

TABLE (4.4)

THE RESULTS OF THE T-TEST ON THE POST-EXPERIMENT WRITING

\begin{tabular}{llll}
\hline Sig. & & & \\
$\mathrm{T}$ & $\mathrm{df}$ & $(2$-tailed) & Mean Difference \\
\hline 8.194 & 58 & .000 & 4.03333 \\
\hline
\end{tabular}

By studying table 4.4 one can find out that the amount of t-observed is significant at the probability level of $\mathrm{p}=.000$.

The results show that there is a significant relationship between the ability to write in the second language and the first language. In fact, in this study, students who knew a second language were better able to write in their first language. The findings are in line with Cummins (1991) who states that skills in L1 and L2 are at least partially interdependent. Providing enough exposure and motivation to learn and transfer is possible from one language to another. According to Cummins' interdependence hypothesis, transfer from L2 to L1 occurs. So, language abilities are developed in one language and transferred to the other.

In this study, English major students were better able to write in their L1 and they considered skills such as, vocabulary choice, structural well-formedness, punctuation, and style in their writing while non-English major students did not. This finding is in agreement with Bialystok (2001) who found that L2 user children have more precocious metalinguistic skills than their monolingual peers.

On the whole the results of the present study showed that a person with two grammatical systems is better able to manipulate language more easily and more effective than can a monolingual person.

\section{CONCLUSION}

The present study aimed to measure the effect of second language writing ability on first language writing ability. To this end, two groups of male and female freshmen university students (English major and non-English major) were asked to write a descriptive writing about 200 words on a topic in their first language (Persian). The topic for both groups was the same. Then, the students studying English had a course in L2 paragraph and essay writing. After passing the course in L2 (English) writing (that is, grammar and writing course 1) by the students studying English, both groups were asked to write on the same topic in their first language (Persian) again. Afterward, two qualified Persian literature raters were asked to score writings.

Persian writings were scored on a scale of 0 to 20 by the raters. The criteria which were taken into consideration in the writings were reasoning, understanding the purpose of the task, vocabulary-choice, structural well-formedness, developing ideas, presenting connected ideas, punctuation, and style. After scoring the writings and comparing the results of the study, the researcher came to the conclusion that English major students were better able to write in their L1. In other words, English major students, after having a course in writing, could write better. Thus, it could be concluded that there is transfer of knowledge and learning processes across languages.

\section{REFERENCES}

[1] Bialystok, E. (2001). Bilingualism in development: Language, literacy, and Cognition. New York: Cambridge University Press.

[2] Cummins, J. (1976). Linguistic interdependence and the educational Development of bilingual children. Review of Educational Research, 49 (2), 222-251.

[3] Cummins, J. (1978a). Bilingualism and the development of metalinguistic awareness. Journal of Cross-Cultural psychology, 9(2), 131-149.

[4] Cummins, J. (1979). Cognitive/academic language proficiency, linguistic interdependence, the optimum age question and some age matters. Working papers on bilingualism, No.19, 121-129.

[5] Cummins, J. (1980). The cross-lingual dimensions of language proficiency: Implications for bilingual education and the optimal age question. TesolQuaterly, 14,175-187.

[6] Cummins, J. (1983). Language proficiency, biliteracy and French immersion. Canadian Journal of Education, 8 (2), 117-138.

[7] Cummins, J. (1984). Bilingualism and special education: Issues in assessment and pedagogy. (Vo1.6). Clevedon: Multilinguall Matters.

[8] Cummins, J. (1991). Interdependence of first-and second-language proficiency in bilingual children. In E. Bialystok (Ed.), language processing in bilingual children (pp. 70-89). Cambridge: Cambridge University press.

[9] Cummins, J. (1996). Negotiation identities: Education for empowerment in a diversesociety. (1st ed). Ontario, CA: California Association for Bilingual Education.

[10] Genesee, F. (1979). Acquisition of reading skills in immersion programs. Foreign Language Annals, 12, 71-77. 
[11] Genesee, F., Tucker G .R. \& Lumbert, W. (1975). Communication skills of bilingual children. Child Development, 46, 10101014.

[12] Geva, E. \& Ryan E. B. (1993). Linguistic and Cognitive Correlates of Academic Skills in First and Second Languages. Language Learning, 43 (1, March), 5-42.

[13] Grice, H.P. (1975). Logic and Conversation. In Martinich, A.P. (ed.). Philosophy of language. (pp. 165-175) New York, NY: Oxford University Press.

[14] Harley, B., Cummins, j., Swain, M., \& Allen, P. (1990). The nature of language proficiency. In B. Harley, P. Allen, j. Cummins, \& M. Swain (Eds.). The development of second language proficiency (pp. 7-25). Cambridge: Cambridge University press.

[15] Lambert, W.E. (1964). Culture and language as factors in learning and instruction. In F. Aboud @ J. Meade (Eds.), cultural factors in learning and education (pp. 99-122). Bellingham, WA: Fifth Western Washington Symposium on Learning.

[16] Lambert, W. E. (1975). Culture and language as factors in learning and education. In A. Wolfgang (Ed.). Education of immigrant students (pp. 55- 83). Toronto: Ontario Institute for Studies in Education.

[17] Lambert, W. E. (1990). Persistent issues in bilingualism. In B. Harley, P. Allen, j. Cummins, \& M Swain (Eds) .The development of second language proficiency. Cambridge, England: Cambridge University press.

[18] Lambert, W. E. (1992). Challenging established views on social issues: The power and limitations of research. American Psychologist, 47, 533 - 542.

[19] Lambert, W. E., \& Tucker R. G. (1972). Bilingual education of children. The St. Lambert experiment. Rowley, Mass.: Newbury House.

[20] Leki, I., Cumming, A., \& Silva, T. (2008) .A Synthesis of Research on Second Language Writing. London: Routledge.

[21] Marsh, H.w. (2000). Late Immersion and Language of Instruction in Hong Kong High School: Achievement Growth in Language and Nonlanguage Subjects. Harward Educational Review, 70 (3), 303-346.

[22] Omaggio Hadley, A. (1993) .Teaching language in context. Boston, Hainle \& Hainle.

[23] Swain, M., \& Lapkin, S. (1982). Evaluating Bilingual Education: A Canadian Case Study. Clevedon: Multilingual Matters.

[24] Skutnabb-Kangas, T., \& Toukomaa, P. (1976). Teaching migrant children's mother tongue and learning the language of the host country in the context of the socio-cultural situation of the migrant family. Helsinki: The Finish National Commission for UNESCO.

[25] Verhoeven, L. t. (1994). Transfer in bilingual development: The linguistic interdependence hypothesis revisited. Language learning, 44, 381- 415.

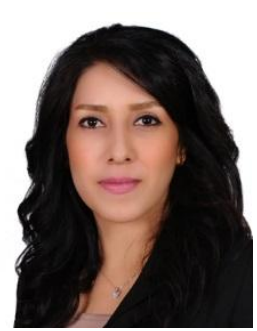

Nastaran Mehrabi. Isfahan, Iran, 1980. Master's degree in English language teaching (TESOL), Khorasgan University, Isfahan, Iran, 2011.

She has worked as an ESOL Teacher in different language institutes in Isfahan, Iran. 